\title{
Effects of reduction of the number of primordial follicles on follicular development to achieve puberty in female rats
}

\author{
M. Shirota ${ }^{1,2}$, S. Soda ${ }^{2}$, C. Katoh ${ }^{2}$, S. Asai ${ }^{3}$, M. Sato ${ }^{1}$, R. Ohta ${ }^{1}$, G. Watanabe ${ }^{3}$, \\ K. Taya ${ }^{3}$ and K. Shirota ${ }^{2}$ \\ ${ }^{1}$ Hatano Research Institute of Food and Drug Safety Centre, Hadano, Kanagawa 257-8523, Japan; \\ ${ }^{2}$ Research Institute of Biosciences, Azabu University, Sagamihara, Kanagawa 229-8501, Japan; and \\ ${ }^{3}$ Laboratory of Veterinary Physiology, Tokyo University of Agriculture and Technology, Fuchu,
}

Tokyo 183-8509, Japan

Effects of reduction of the number of primordial follicles on follicular development and concentrations of circulating hormones were examined in immature female rat offspring of dams given busulfan intraperitoneally on day 14 of gestation. The offspring of dams treated with $5 \mathrm{mg}$ busulfan $\mathrm{kg}^{-1}$ showed vaginal opening at an age comparable with the offspring of dams treated with $2.5 \mathrm{mg}$ busulfan $\mathrm{kg}^{-1}$ or with corn oil as a control, although they exhibited an irregular oestrous cycle until week 14 after birth. The serum concentrations of immunoreactive inhibin and FSH on day 26 after birth of the offspring treated with $5 \mathrm{mg}$ busulfan $\mathrm{kg}^{-1}$ were similar to those of age-matched controls. On day 15 after birth, however, the concentration of their immunoreactive inhibin was markedly lower than that of controls, whereas the concentration of their FSH was increased inversely. Comparison of the numbers of ovarian follicles in the controls and groups treated with $2.5 \mathrm{mg}$ busulfan $\mathrm{kg}^{-1}$ and $5 \mathrm{mg}$ busulfan $\mathrm{kg}^{-1}$ revealed that prenatal treatment with busulfan reduced the number of follicles in the primordial or primary phase and in the preantral phase on day 7 after birth. Although the increase of the ratio of the number of preantral follicles during days 7-13 after birth tended to vary with the prenatal dose of busulfan, the number of preantral follicles in the group treated with $5 \mathrm{mg}$ busulfan $\mathrm{kg}^{-1}$ was still smaller than in the controls. The concentration of serum immunoreactive inhibin of the offspring treated with busulfan was reduced on day 7 after birth without alteration of the concentration of gonadotrophin. On day 13 after birth, the concentration of serum immunoreactive inhibin was reduced only in the offspring treated with $5 \mathrm{mg}$ busulfan $\mathrm{kg}^{-1}$, and the concentration of serum FSH of the offspring was increased inversely as found on day 15 after birth. These results indicate that a reduction in the number of primordial follicles decreases the number of follicles that enter the growing phase, a major source of circulating inhibin in the neonatal and infantile ovary, and that consequently increased circulating FSH may accelerate follicular development to achieve puberty.

\section{Introduction}

Primordial follicles constitute a stockpile of nongrowing follicles in most mammalian species. The size of the stockpile varies among species; however, there is no known exception to the rule that the stockpile progressively decreases during the fertile life by conversion of the primordial follicles into growing follicles. The initial recruitment from the stockpile to the growing pool begins after follicle formation and occurs continuously throughout the fertile lifespan, whereas antral follicles are recruited at specific intervals after puberty depending on species (for review, see McGee

Email: shirota.m@fdsc.or.jp and Hsueh, 2000). The mechanisms controlling the recruitment from the primordial follicle to the primary follicle and further growth during the neonatal and infantile periods are not well understood, as compared with those concerning the cyclic recruitment of antral follicles under hormonal control.

Morphological observations have revealed that a reduction in the number of primordial follicles accelerates follicular growth in intact mice and mice treated with ovotoxic agents (Krarup et al., 1969), rats that were unilaterally ovariectomized (Meredith et al., 1992) and pre-menopausal women with small preservation of the primordial follicles in the ovary (Richardson et al., 1987). In pre-menopausal women, some endocrine events, such as a decrease in concentration of inhibin and an increase in $\mathrm{FSH}$, may lead to accelerated follicular growth (for review, see Wise et al., 1996; Burger, 1999). 
An increase in the concentration of circulating FSH was also shown before depletion of the number of ovarian follicles in adult female mice given 4-vinylcyclohexene $(\mathrm{VCH})$, of which the epoxide-metabolite is ovotoxic (Hooser et al., 1994), and in aged rats exhibiting persistent vaginal cornification (Lu et al., 1979).

Treatment of rats with busulfan, an alkylating agent, during the period of germ cell proliferation reduces the number of oogonia (Merchant, 1975), and consequently reduces the number of primordial follicles formed in the ovary (Hirshfield, 1994). Hirshfield (1994) found an inverse correlation between the number of primordial follicles in the ovary and the rate at which they moved into the growing pool. However, it is not known whether endocrinological events similar to those found in premenopausal women and in adult or aged rodents occur in rats treated with busulfan during the period when the first wave of follicles develops from a primordial follicle stockpile of finite size for the first ovulation. The first aim of the present study was to determine the doses of busulfan that would allow the recruitment of primordial follicles from a small stockpile such that they would be mature for the first ovulation but would exhibit different prognoses for reproduction after puberty. The second aim was to determine the concentrations of circulating hormones, including immunoreactive (ir)-inhibin, FSH, $\mathrm{LH}$ and oestradiol, and the number of ovarian follicles in immature rats treated with busulfan to compare the stepwise development of follicles among ovaries with different sizes of primordial follicle stockpile. The present results may provide new insight into the mechanisms of acceleration of follicular growth in ovaries with a small primordial follicle stockpile.

\section{Materials and Methods}

\section{Chemicals}

Busulfan (Sigma, St Louis, MO) was weighed for every concentration, and was triturated in a mortar to suspend it in a small amount of corn oil (Nakarai Tesque, Kyoto). The suspended busulfan was collected into a measuring tube by washing it with corn oil, and concentrations of busulfan were adjusted for use at a constant volume of $5 \mathrm{ml} \mathrm{kg}-1$ of maternal body mass.

\section{Animals}

All procedures described here were approved by a local ethics committee (the Committee on Animal Care and Use in the Hatano Research Institute of the Food and Drug Safety Centre). Adult female Sprague-Dawley rats and their mating partners of the same strain were purchased from Charles River Japan (Atsugi, Kanagawa). These animals were maintained under $12 \mathrm{~h}$ light: $12 \mathrm{~h}$ dark cycle (lights on 07:00-19:00 h) in an animal husbandry facility in which temperature and humidity were controlled at $23-25^{\circ} \mathrm{C}$ and $50-65 \%$, respectively. The animals were housed individually in cages and were supplied with pellet chow (CE-2, Clea Japan Inc., Tokyo) and water (tap water) ad libitum. After acclimatization to the environment, the animals were mated, and the day on which spermatozoa were confirmed in the vagina was defined as day 0 of gestation. Pregnant females were administered busulfan intraperitoneally (i.p.) on day 14 of gestation, and were allowed to deliver spontaneously. The size of each litter was standardized to eight on day 1 after birth and offspring were weaned on day 21 after birth. Control offspring were obtained from dams given $5 \mathrm{ml}$ corn oil $\mathrm{kg}^{-1}$ i.p. on day 14 of gestation.

\section{Experiment 1}

Female offspring from 3-11 dams given corn oil or $2.5,5$ or $10 \mathrm{mg}$ busulfan $\mathrm{kg}^{-1}$ were examined for vaginal opening, and the body weight was recorded at the time of vaginal opening. Sixteen, 14 and 13 offspring in the groups treated with oil, 5 or $10 \mathrm{mg}$ busulfan $\mathrm{kg}^{-1}$, respectively, were killed on the day of vaginal opening, and the numbers of oocytes were counted in the animals in which freshly ovulated oocytes were found in the ampullae by the method of Burdick and Whitney (1941). The masses of the ovaries and uterus were determined in these offspring. Ovarian masses were also measured either on days 15 or 24 , or weeks 7 or 14 after birth. All of the offspring in the group treated with $10 \mathrm{mg}$ busulfan $\mathrm{kg}^{-1}$ were killed at week 7 after birth.

Before necropsy on week 14 after birth, offspring were examined for oestrous cycle by monitoring vaginal cytology daily from week 10 after birth. The pattern of the oestrous cycle was categorized as being either a 4 or 5 day cycle, in which oestrus occurred only at intervals of 4 or 5 days, or an irregular cycle. The irregular cycle included all cycles other than a 4 or 5 day cycle. For the above necropsies, the offspring were killed by being bled under ether anaesthesia.

\section{Experiment 2}

In the female offspring from five or eight dams given corn oil or $5 \mathrm{mg}$ busulfan $\mathrm{kg}^{-1}$, respectively, individual serum concentrations of ir-inhibin and FSH were determined on days 15 or 26 after birth. Trunk blood was obtained after decapitation, from which serum samples were prepared by centrifugation at $1040 \mathrm{~g}$ at $4{ }^{\circ} \mathrm{C}$ for $20 \mathrm{~min}$, and then stored at $-20^{\circ} \mathrm{C}$ until concentrations of hormones were determined by radioimmunoassay.

\section{Experiment 3}

Serum concentrations of ir-inhibin, FSH, LH and oestradiol and the numbers of ovarian follicles were determined on days 7 and 13 after birth in female offspring from four dams given corn oil, or five dams 
given 2.5 or $5 \mathrm{mg}$ busulfan $\mathrm{kg}^{-1}$, respectively. Serum samples were prepared as described in Expt 2. Serum concentrations of the hormones were determined in individual offspring on day 13 after birth, whereas they were determined in individual litters on day 7 after birth by combining serum samples from three to five female offspring in the same litter.

Ovaries dissected from these offspring were stored in $70 \%$ ethanol after fixation for $12 \mathrm{~h}$ in Bouin's solution, and were embedded in paraffin wax according to standard procedures. Bilateral ovaries of three female offspring from three different dams were examined to determine the number of follicles in each group. The specimens were cut serially into sections of $6 \mu \mathrm{m}$ in thickness and stained with haematoxylin and eosin. Every fifth section starting with the first section that contained a follicle, was selected for classification. Only follicles that contained oocytes with a nucleolus were classified as primordial or primary, preantral and early antral follicles according to the classification system of Pederson and Peters (1968). The primordial or primary, preantral and early antral follicles correspond to types 2-3b, 4-5b and 6 of their classification system, respectively. The sections were counted twice, and the averages of the two replicate counts of the sections from the ovaries of both sides were calculated as the numbers of each type of follicle.

\section{Radioimmunoassays}

Serum concentrations of $\mathrm{FSH}, \mathrm{LH}$, ir-inhibin and oestradiol were determined using double-antibody radioimmunoassay systems with an ${ }^{125} \mathrm{I}$-labelled radioligand.

Serum concentrations of FSH and $\mathrm{LH}$ were measured using National Digestive and Kidney Disease (NIDDK) radioimmunoassay kits for rat FSH and LH (NIAMDD, $\mathrm{NIH}$, Bethesda, MD) as described by Taya et al. (1983). The iodinated preparations used were rat FSH$\mathrm{I}-5$ and $\mathrm{LH}-\mathrm{I}-7$, and the antisera were anti-rat-FSH-S-11 and $\mathrm{LH}-\mathrm{S}-10$, respectively. The results were expressed with respect to NIDDK rat FSH-RP-2 and LH-RP-2, respectively. The intra- and interassay coefficients of variation were 3.4 and $5.3 \%$ for $\mathrm{FSH}$ and 7.2 and $11.2 \%$ for $\mathrm{LH}$, respectively.

Serum concentrations of ir-inhibin were measured as described by Hamada et al. (1989). The iodinated preparation used was purified 32 kDa bovine inhibin, and the antiserum was anti-bovine inhibin (TNDH-1). The results were expressed in terms of $32 \mathrm{kDa}$ bovine inhibin. The assay system does not distinguish dimeric inhibin from the $\alpha$ subunit monomer. The intraand interassay coefficients of variation were 7.0 and $11.4 \%$, respectively. Serum concentrations of oestradiol were measured as described by Taya et al. (1985). The antiserum against oestradiol (GDN 244) was kindly supplied by G. D. Niswender, (Fort Collins, CO). The intra- and interassay coefficients of variation were 4.1 and $6.6 \%$, respectively.

\section{Statistical analysis}

The significance of differences was analysed by Dunnett's test when values were obtained from more than three groups. When values were obtained from two groups, Student's $t$ test was used to analyse the significance of difference after confirming the uniformity of variance by the $F$ test. When the variance was not uniform, the Aspin-Welch $t$ test was applied. A $P$ value $<$ 0.05 was considered to be statistically significant.

\section{Results}

Puberty and reproductive prognoses of offspring treated with busulfan

The features of puberty and the prognoses for reproductive functions of offspring treated with busulfan in utero are summarized (Table 1). Prenatal treatment with $5 \mathrm{mg}$ busulfan $\mathrm{kg}^{-1}$ did not affect the timing of vaginal opening. However, the number of oocytes shed at the first ovulation was slightly reduced (without a significant difference) compared with that in control animals $(P=0.0618)$. Although ovarian masses in this group were small at all ages, they increased until week 7, but declined at week 14 after birth, and the animal exhibited irregular oestrous cycle, such as persistent oestrus (persistent vaginal cornification).

Prenatal treatment with $2.5 \mathrm{mg}$ busulfan $\mathrm{kg}^{-1}$ affected neither the timing of the vaginal opening nor the ovarian mass at week 14 after birth. Although we did not determine the changes in ovarian mass in this group, the ovarian masses in the busulfan-treated groups at day 13 after birth were significantly lower than those in the control group in Expt 3. Mean ovarian masses $( \pm \mathrm{SEM}, n)$ were $3.2 \mathrm{mg}( \pm 0.3,4)$ in the controls, $2.3 \mathrm{mg}$ $( \pm 0.1,5)$ in the group treated with $2.5 \mathrm{mg}$ busulfan $\mathrm{kg}^{-1}$ and $1.1 \mathrm{mg}( \pm 0.2,4)$ in the group treated with $5 \mathrm{mg}$ busulfan $\mathrm{kg}^{-1}$. Differences in the actual sizes of these ovaries are shown (Fig. 1). Two offspring in this group showed irregular oestrous cycle but prolonged dioestrus, which was also observed in the controls. Thus, prenatal treatment with 2.5 or $5 \mathrm{mg}$ busulfan $\mathrm{kg}^{-1}$ permitted rats to undergo puberty.

In contrast with the effects of these two doses, prenatal treatment with $10 \mathrm{mg}$ busulfan $\mathrm{kg}^{-1}$ induced ovarian exhaustion before puberty in four out of 20 offspring. These four offspring never showed vaginal opening, and their uteri were atrophic at the necropsy at week 7 after birth (3.3-29.1 mg). The timing of vaginal opening in the other 16 offspring was similar to that in the controls; however, body weight measured on the day of vaginal opening was significantly lower than that of the controls $(P<0.0001)$. Four of the 13 offspring killed on the 
Table 1. Puberty and prognoses of female reproduction in offspring of rat dams given busulfan or corn oil (control) i.p. on day 14 of gestation

\begin{tabular}{|c|c|c|c|c|}
\hline & \multicolumn{4}{|c|}{ Dose of busulfan $\left(\mathrm{mg} \mathrm{kg}^{-1}\right)$} \\
\hline & 0 (Control) & 2.5 & 5.0 & 10.0 \\
\hline \multicolumn{5}{|l|}{ Vaginal opening } \\
\hline Number of animals with vaginal opening ${ }^{\mathrm{a}}$ & $26 / 26$ & $7 / 7$ & $22 / 22$ & $16 / 20$ \\
\hline Age at vaginal opening (day after birth) ${ }^{b}$ & $34.0 \pm 0.5(26)$ & $34.4 \pm 1.6(7)$ & $34.6 \pm 0.5(22)$ & $34.1 \pm 0.6(16)$ \\
\hline Body weight at vaginal opening $(g)^{b}$ & $118.1 \pm 2.7(26)$ & $123.7 \pm 5.9(7)$ & $109.5 \pm 4.0(22)$ & $97.8 \pm 3.4(16)^{* *}$ \\
\hline \multicolumn{5}{|l|}{ First ovulation ${ }^{b}$} \\
\hline Body weight (g) & $114.2 \pm 8.6(6)$ & ND & $108.6 \pm 4.8(9)$ & $107.2 \pm 3.0(4)$ \\
\hline Number of oocytes shed & $13.0 \pm 0.7(6)$ & ND & $10.9 \pm 0.4(9)$ & $3.5 \pm 1.3(4)^{* *}$ \\
\hline Ovarian mass (mg) & $32.4 \pm 1.2(6)$ & ND & $20.3 \pm 1.6(9)^{* *}$ & $4.6 \pm 1.6(4)^{* *}$ \\
\hline Uterine mass (mg) & $167.8 \pm 4.1(6)$ & ND & $155.4 \pm 4.3(9)$ & $167.9 \pm 7.9(4)$ \\
\hline \multicolumn{5}{|l|}{ Ovarian mass $(\mathrm{mg})^{\mathrm{b}, \mathrm{c}}$} \\
\hline Day 15 after birth & $3.2 \pm 0.2(3)$ & ND & $1.2 \pm 0.2(4)^{* *}$ & ND \\
\hline Day 24 after birth & $14.2 \pm 1.6(3)$ & ND & $10.9 \pm 1.5(4)$ & ND \\
\hline Week 7 after birth & $61.5 \pm 2.8$ & ND & $37.7 \pm 9.6(3)^{*}$ & $4.5 \pm 1.3(3)^{* * d}$ \\
\hline Week 14 after birth & $77.1 \pm 4.7(7)$ & $85.9 \pm 5.4(7)$ & $15.9 \pm 4.1(5)^{* *}$ & ND \\
\hline \multicolumn{5}{|l|}{ Oestrous cycle during weeks 10-14 after birth ${ }^{\mathrm{a}}$} \\
\hline 4- or 5-day cycle & $6 / 7$ & $5 / 7$ & $0 / 5$ & ND \\
\hline Irregular cycle & $1 / 7$ & $2 / 7$ & $5 / 5$ & ND \\
\hline
\end{tabular}

a Values represent number of animals examined of the total animals examined.

${ }^{b}$ Values represent the mean \pm SEM and numbers in parentheses the number of animals.

${ }^{c}$ Data are from offspring with freshly ovulated oocytes in the ampullae at the necropsy on the day of vaginal opening.

${ }^{\mathrm{d}}$ Values were calculated from three offspring with measurable ovary among seven offspring.

${ }^{*} P<0.05$ and ${ }^{* *} P<0.01$ compared with control values by Dunnett's test or Student's $t$ test.

ND: Not determined.

day of vaginal opening showed a first ovulation with significantly fewer oocytes shed as compared with the number in the controls $(P<0.0001)$.

Uterine mass at the first ovulation was similar among the groups regardless of the number of oocytes shed and of the ovarian mass at the first ovulation.

\section{Changes in circulating concentrations of ir-inhibin and FSH before puberty}

The serum concentration of ir-inhibin in the group treated with $5 \mathrm{mg}$ busulfan $\mathrm{kg}^{-1}$ was significantly lower than that in controls on day 15 after birth $(P=0.0001)$, but was increased to a concentration not significantly different from that in the controls on day 26 after birth (Fig. 2). In the group treated with $5 \mathrm{mg}$ busulfan $\mathrm{kg}^{-1}$, the concentration of circulating FSH changed in an inverse manner to that of ir-inhibin, and by day 15 after birth was significantly higher than that in the controls $(P=$ 0.0433).

Comparison between numbers of ovarian follicles in the offspring treated with different doses of busulfan in utero

Representative photographs of the ovaries in which the number of follicles was determined are shown (Fig. 1), and the number of follicles in these ovaries is summarized (Table 2). The follicles were categorized according to the classification system of Pederson and Peters (1968) but follicles of types 2 (primordial) and 3 (primary), and types 4 and 5 (preantral) were not distinguished. Prenatal treatment with busulfan severely reduced the number of primordial or primary follicles. In addition to a decrease in the number of these follicles, the number of preantral follicles in the busulfan-treated ovaries was significantly smaller than that in the controls on day 7 after birth $(P=0.0001$ and $P<0.0001$ in the groups treated with 2.5 and $5 \mathrm{mg}$ busulfan $\mathrm{kg}^{-1}$, respectively. Furthermore, there was an inverse correlation between the dose of busulfan and the number of preantral follicles on day 7 after birth (correlation coefficient $=-0.983$ ). The increase in the ratio of the number of preantral follicles from days 7 13 after birth tended to vary according to the prenatal dose of busulfan, and the number of these follicles in the group treated with $5 \mathrm{mg}$ busulfan $\mathrm{kg}^{-1}$ was significantly larger on day 13 than on day 7 after birth $(P=0.0019)$. Although the number of these follicles in the ovaries of the group treated with $2.5 \mathrm{mg}$ busulfan $\mathrm{kg}^{-1}$ was similar to that in the controls, in the group treated with $5 \mathrm{mg}$ busulfan $\mathrm{kg}^{-1}$, the number was still significantly smaller than that in the controls on day 13 after birth $(P=0.0054)$. Follicles categorized in the early antral phase were found in the ovary on day 13 after birth, and no differences were found in the number of follicles in this phase between busulfan-treated and control ovaries. 
Table 2. Number of ovarian follicles in offspring of rat dams given busulfan or corn oil (control) i.p. on day 14 of gestation

\begin{tabular}{|c|c|c|c|}
\hline & \multicolumn{3}{|c|}{ Dose of busulfan ( $\left.\mathrm{mg} \mathrm{kg}^{-1}\right)$} \\
\hline & 0 (Control) & 2.5 & 5.0 \\
\hline \multicolumn{4}{|c|}{ Number of follicles on day 7 after birth ${ }^{a}$} \\
\hline Primordial/primary & $4061.3 \pm 371.7(3)$ & $302.2 \pm 151.6(3)^{* *}$ & $10.0 \pm 4.8(3)^{* *}$ \\
\hline Preantral & $191.8 \pm 8.7(3)$ & $103.8 \pm 8.0(3)^{* *}$ & $16.5 \pm 11.0(3)^{* *}$ \\
\hline Early antral & $0(3)$ & $0(3)$ & $0(3)$ \\
\hline \multicolumn{4}{|c|}{ Number of follicles on day 13 after birth ${ }^{a}$} \\
\hline Primordial/primary & $3150.3 \pm 609.1$ & $445.8 \pm 201.4(3)^{* *}$ & $17.0 \pm 2.8(3)^{* *}$ \\
\hline Preantral & $203.5 \pm 18.9(3)$ & $147.2 \pm 36.1(3)$ & $35.8 \pm 12.9(3)^{* *}$ \\
\hline Early antral & $25.7 \pm 8.8(3)$ & $27.0 \pm 13.6(3)$ & $2.0 \pm 2.0(3)$ \\
\hline
\end{tabular}

${ }^{a}$ Values represent the mean number of follicles \pm SEM and numbers in parentheses the number of animals.

**P $P$.01 compared with control values by Dunnett's test.
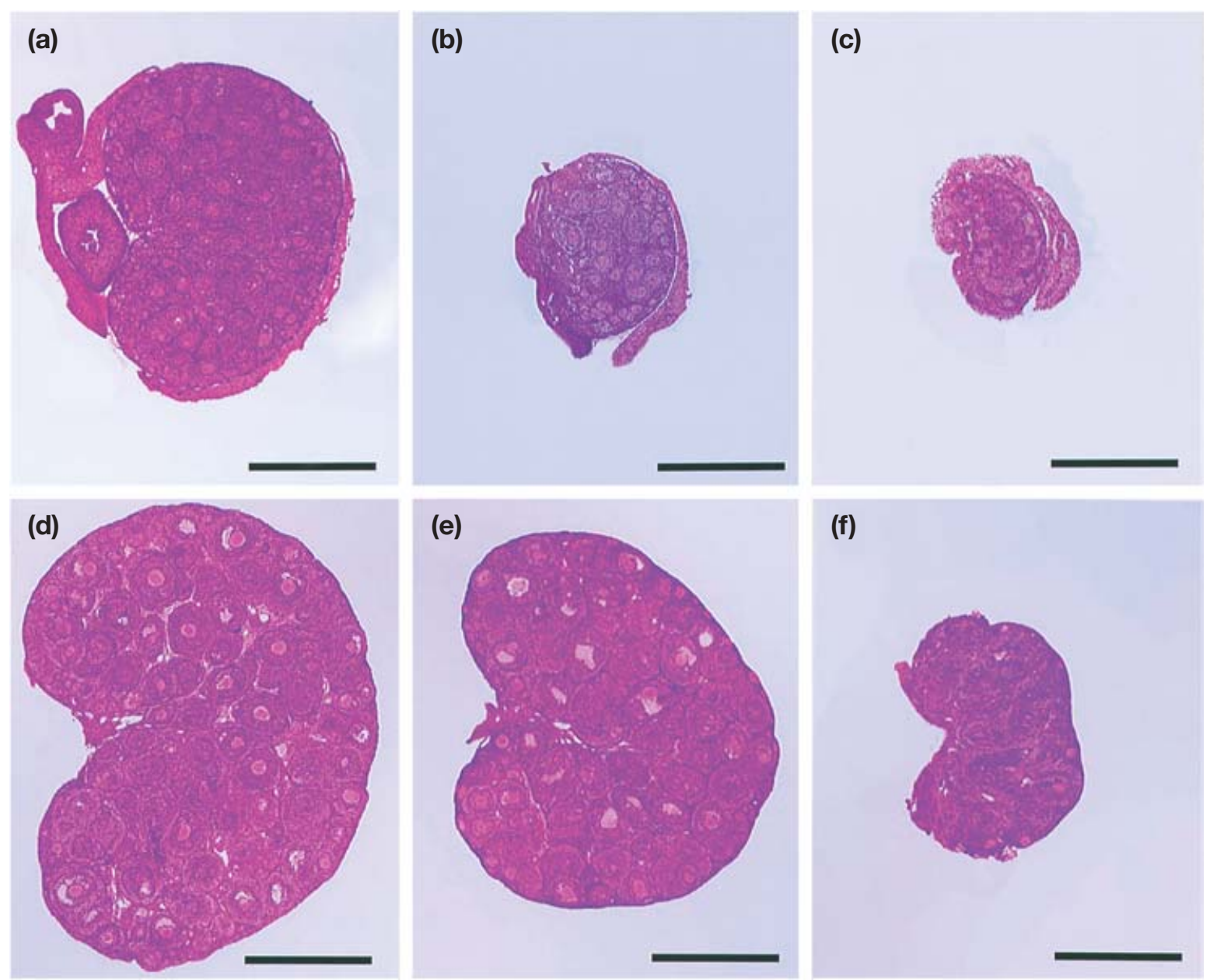

Fig. 1. Photographs of representative ovarian sections stained by haematoxylin-eosin in offspring from rat dams given (a,d) corn oil, (b,e) $2.5 \mathrm{mg}$ busulfan $\mathrm{kg}^{-1}$ or (c,f) $5 \mathrm{mg}$ busulfan $\mathrm{kg}^{-1}$ i.p. on day 14 of gestation. A reduction in the actual size of the ovary is noted in the ovaries treated with busulfan. The photographs of (a), (b) and (c) were obtained on day 7 after birth and those of (d), (e) and (f) were obtained on day 13 after birth. Scale bars represent $500 \mu \mathrm{m}$. 
(a)

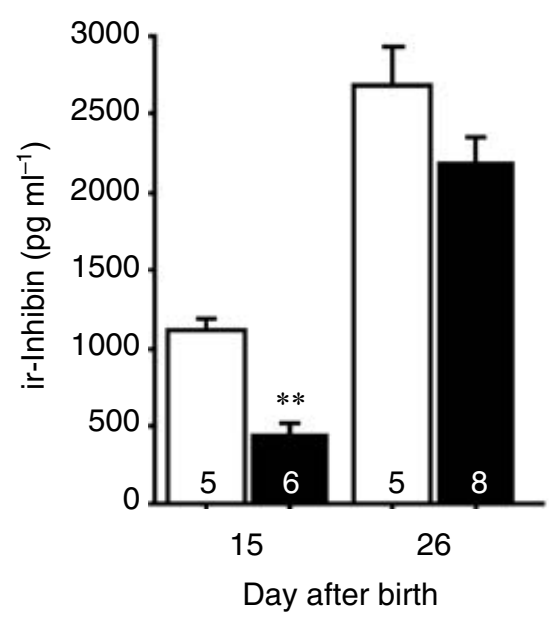

(b)

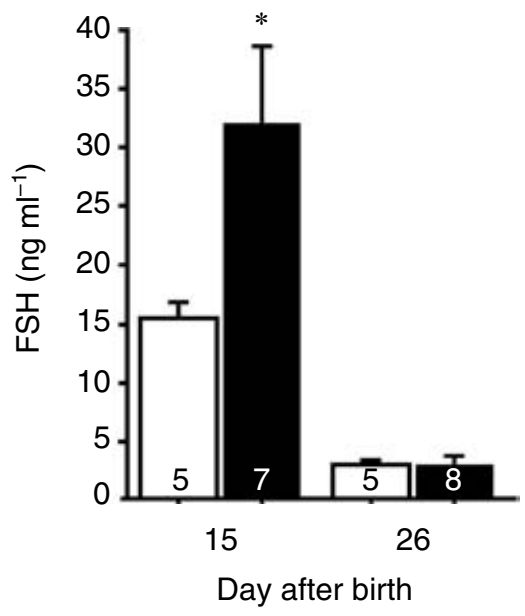

Fig. 2. Serum concentrations of (a) immunoreactive (ir)-inhibin and (b) FSH on days 15 and 26 after birth in offspring of rat dams given corn oil ( $\square$ ) or 5 mg busulfan $\mathrm{kg}^{-1}$ (苗) i.p. on day 14 of gestation. Columns and vertical bars represent mean $( \pm S E M)$. Numbers in columns indicate the number of samples examined. ${ }^{*} P<0.05$ and ${ }^{* *} P<0.01$ compared with age-matched control values by Aspin-Welch's $t$ test.

(a)

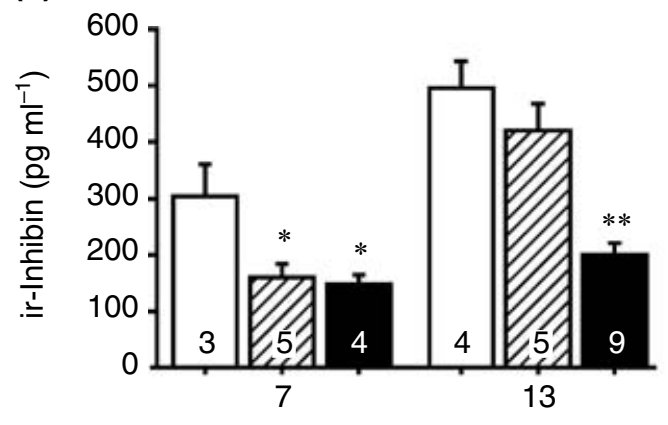

Day after birth

(c)

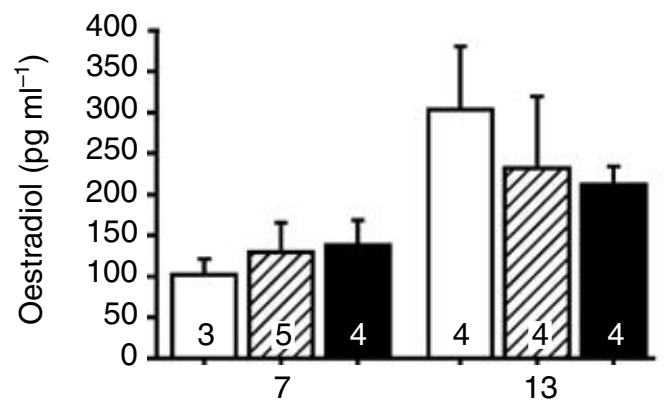

Day after birth (b)

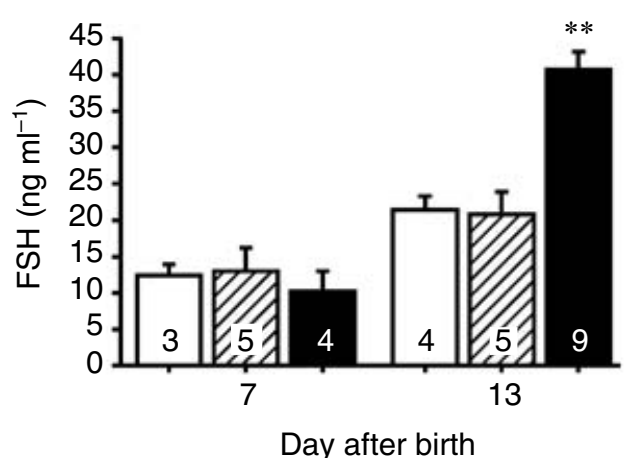

(d)

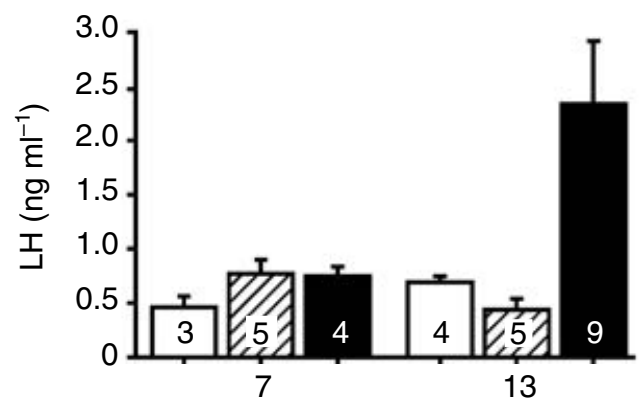

Day after birth

Fig. 3. Serum concentrations of (a) immunoreactive (ir)-inhibin, (b) FSH, (c) oestradiol and (d) LH on days 7 and 13 after birth in offspring of rat dams given corn oil ( $\square$ ) or $2.5 \mathrm{mg}$ busulfan $\mathrm{kg}^{-1}$ ( busulfan $\mathrm{kg}^{-1}(\boldsymbol{\square})$ i.p. on day 14 of gestation. Columns and vertical bars represent the mean $( \pm$ SEM). Numbers in columns indicate the number of samples examined. ${ }^{*} P<0.05$ and ${ }^{* *} P<0.01$ compared with age-matched control values by Dunnett's test. 
Comparison of circulating concentrations of ir-inhibin, FSH, LH and oestradiol between offspring treated with different doses of busulfan in utero

Changes in the concentrations of circulating hormones of the offspring treated with busulfan are shown (Fig. 3). On day 7 after birth, serum concentrations of ir-inhibin were significantly reduced in the groups treated with busulfan, but not in a dose-related manner (Fig. 3a; $P=0.0174$ and $P=0.0146$ in the groups treated with 2.5 and $5 \mathrm{mg}$ busulfan $\mathrm{kg}^{-1}$, respectively). There were no differences in the concentrations of other hormones on day 7 after birth. On day 13 after birth, the serum concentration of ir-inhibin was reduced only in the group treated with $5 \mathrm{mg}$ busulfan $\mathrm{kg}^{-1}(P<0.0001)$, whereas that of $\mathrm{FSH}$ was increased in this group (Fig. 3b; $P=0.0005)$. There were no differences in the serum concentrations of oestradiol between the control groups and those treated with busulfan (Fig. 3c). The serum concentration of $\mathrm{LH}$ tended to increase in this group; however, no significant difference was observed (Fig. 3d; $P=0.0559)$.

\section{Discussion}

The present study clearly demonstrated that the number of preantral follicles was reduced in the neonatal rat ovary by the prenatal treatment with busulfan in a manner related to the dose. Although the numbers of primordial and primary follicles were not counted separately, it was obvious that the treatment reduced the number of the primordial follicles, as shown by Hirshfield (1994). Thus, the present study indicates that a smaller-sized growing pool was formed in the ovary with the smaller-sized stockpile. The number of primary follicles may also be reduced in the ovaries from rats treated with busulfan.

In spite of the smaller number of the growing follicles, the rate of the follicular recruitment seemed to be accelerated in the ovaries from rats treated with busulfan, as reported by Hirshfield (1994). The number of preantral follicles in the ovaries from rats treated with $2.5 \mathrm{mg}$ busulfan $\mathrm{kg}^{-1}$ became comparable by day 13 after birth to that in the age-matched controls. The increasing proportion of these follicles from days 7-13 after birth tended to vary according to the prenatal dose of busulfan. Furthermore, the number of oocytes shed at the first ovulation in the group treated with $5 \mathrm{mg}$ busulfan $\mathrm{kg}^{-1}$ was comparable to that in the controls, and the uterine masses were identical among the groups. All of these data indicate that more follicles had developed by the time of puberty from the smaller number of primordial follicles that had moved into the growing pool from the smaller-sized stockpile.

Hirshfield noted an inverse correlation between the number of primordial follicles in the ovary and the rate at which they moved into the growing pool from morphological observations on animals exposed to busulfan in utero (Hirshfield, 1994). The present study further determined the concentrations of humoral factors related to follicular development in the ovary, such as the circulating concentrations of ir-inhibin and oestradiol. The concentration of circulating ir-inhibin was reduced only when the number of the preantral follicles was reduced, such as on day 7 after birth in the groups treated with 2.5 or $5 \mathrm{mg}$ busulfan $\mathrm{kg}^{-1}$ and on day 13 after birth in the group treated with $5 \mathrm{mg}$ busulfan $\mathrm{kg}^{-1}$. In contrast, the concentration of circulating oestradiol was not affected by the prenatal treatment with busulfan. Since healthy growing follicles, including primary, preantral and antral follicles, contribute to the production of bioactive dimeric inhibins and the inactive $\alpha$ subunit (Drummond et al., 2000; Herath et al., 2001), the concentration of inhibin may reflect the number of primary and preantral follicles until antral follicle formation in the ovary.

Inhibin is a regulatory peptide that inhibits $\mathrm{FSH}$ synthesis and release from the pituitary. As reported in previous studies (Döhler and Wuttke, 1974, 1975; Dahl et al., 1988; Herath et al., 2001), the concentration of serum FSH in controls in the present study was also extremely high in the infants. An incomplete inhibinfeedback system during this period is believed to result in the high concentration of circulating FSH. Surprisingly, the serum concentrations of $\mathrm{FSH}$ in the group treated with $5 \mathrm{mg}$ busulfan $\mathrm{kg}^{-1}$ were further increased on days 13 and 15 after birth, when the concentration of circulating ir-inhibin was reduced. In contrast, the serum concentrations of FSH on day 7 after birth were identical among the groups, whereas the concentration of circulating ir-inhibin was reduced in the groups treated with busulfan. These results indicate that the inhibinfeedback system may have established during days 7-13 after birth in the female rat.

Although ovarian follicles can develop until preantral phase without FSH signalling in FSH receptor gene null mutant mice (Abel et al., 2000), FSH does enhance early follicular cell development and early oocyte growth. A reduction in the concentration of circulating FSH during the first 10 days of life in rats as a result of injection of several agents led to a reduction in follicular growth and a gradual loss of growing follicles (Smith and Ojeda, 1986; Fagbohun et al., 1990). As has been suggested in pre-menopausal women, the decrease in concentration of ir-inhibin and increase in concentration of FSH seen in the present study may lead to acceleration of follicular growth in immature rats treated with busulfan. Unlike the case of pre-menopausal women, the concentrations of circulating ir-inhibin and FSH in the rats treated with $5 \mathrm{mg}$ busulfan $\mathrm{kg}^{-1}$ became similar to those in the controls on day 26 after birth when tertiary follicles had developed in the ovary. Finally, the rats treated with $5 \mathrm{mg}$ busulfan $\mathrm{kg}^{-1}$ exhibited persistent vaginal cornification, a typical post-cyclic vaginal status found in the Sprague-Dawley strain of rats (vom Saal et al., 1994) 
at a young age. It seems likely that the concentration of circulating FSH in the rats treated with $2.5 \mathrm{mg}$ busulfan $\mathrm{kg}^{-1}$ increased from days 8-12 after birth, so that the number of preantral follicles was normalized by day 13 after birth. In contrast to the offspring in the above two dose groups, the four offspring in the group treated with $10 \mathrm{mg}$ busulfan $\mathrm{kg}^{-1}$ never showed vaginal opening, possibly because they depleted ovarian follicles before puberty. The ovaries of the other 16 offspring in this group might secrete a sufficient amount of oestradiol to increase uterine mass and to perforate the vaginal canal at normal timing, whereas the number of primordial follicles moving into the growing pool might be too small to provide a sufficient number of Graafian follicles for the first ovulation.

Because the primordial follicle does not express gonadotrophin receptors, gonadotrophins have no effect on initiation of follicle growth. Oocytes play an essential role in controlling their own fate by influencing somatic cell functions (for review, see Matzuk, 2000). Several substances that act in a paracrine fashion to promote initial or early recruitment of the follicles (for review, see McGee and Hsueh, 2000) have been identified. Among such substances, $c$-kit, which is expressed in the oocyte of the primordial follicle as a receptor of kit-ligand, is one of the candidate molecules for transducing the information concerning the number of primordial follicles. Follicular recruitment from the primordial follicle was inhibited by inactivation of a kit-ligand (Yoshida et al., 1997) and was enhanced by supplementation of the kit-ligand (Parrott and Skinner, 1999). The present experimental conditions may have mimicked the inhibition of signalling cascades mediated by the kit-ligand receptor by administering anti$c$-kit antiserum to neonatal mice (Yoshida et al., 1997). Several members of the gene family of transforming growth factor $\beta$ (TGF- $\beta$ ), such as anti-Müllerian hormone $(\mathrm{AMH})$, growth differentiation factor 9 (GDF-9) and bone morphogenetic protein 7 (BMP-7), can also affect primordial follicle recruitment (Durlinger et al., 1999, 2002; Vitt et al., 2000; Lee et al., 2001). AMH is a glycoprotein hormone responsible for regression of Müllerian ducts in developing male embryos. In female rats, $\mathrm{AMH}$ and its type II receptor are expressed in the granulosa cells of healthy growing follicles (Ueno et al., 1989; Baarends et al., 1995). In the ovaries of $\mathrm{AMH}$-deficient mice, more primordial follicles are recruited and show early depletion of their stockpile of primordial follicles (Durlinger et al., 1999). Furthermore, cultured neonatal mouse ovaries contain fewer growing follicles in the presence of AMH (Durlinger et al., 2002). Thus AMH acts as an inhibitory growth factor in the ovary during the early stage of folliculogenesis. In contrast, GDF-9 is expressed in the mammalian oocytes beginning at the primary stage, and GDF-9deficiency causes an early block in folliculogenesis (Dong et al., 1996). Although the presence of GDF-9 has not been confirmed in the systemic circulation, it stimulates preantral follicle growth in vitro (Hayashi et al., 1999) and stimulates primordial and primary follicle progression in vivo (Vitt et al., 2000). BMP-7 is produced by theca cells, and type I- and type II-BMP receptors are expressed in the granulosa cells and oocytes of growing follicles in the ovaries of cyclic rats (Shimasaki et al., 1999). Whereas BMP-7 attenuates FSH-stimulated oestradiol and progesterone production from the granulosa cells in vitro (Shimasaki et al., 1999), it facilitates the transition of follicles from the primordial stage to the growing pool in immature rats (Lee et al., 2001). Thus, autocrine and paracrine factors may affect the primordial follicle recruitment, and the present model of busulfan treatment might be a good animal model to study how various substances are involved in the primordial and primary follicle progression.

The concentration of circulating ir-inhibin on day 13 after birth closely reflected the number of the preantral follicles and on day 7 it was reduced in rats treated with 2.5 and $5 \mathrm{mg}$ busulfan $\mathrm{kg}^{-1}$, but there was little correlation with the numbers of preantral follicles found. The immunohistochemical study revealed that the $\alpha, \beta A$ and $\beta B$ subunits of inhibin, which constitute dimeric inhibin, were localized to primary, secondary, antral and large antral follicles in the immature rat ovary, including those on day 5 after birth (Herath et al., 2001). However, the $\alpha$ subunit was the most prominently stained of the three subunits in the ovary on day 5 after birth. Since the inhibin-radioimmunoassay system used in the present study does not distinguish dimeric inhibins, inhibin A and inhibin B, from the $\alpha$ subunit monomer or inhibin pro- $\alpha \mathrm{C}$, the cause of the doseindependent reduction in the concentration of circulating ir-inhibin on day 7 after birth can be explained if the circulating concentration of the $\alpha$ subunit monomer obscured differences in the concentration of dimeric inhibin between the rats treated with 2.5 and $5 \mathrm{mg}$ busulfan $\mathrm{kg}^{-1}$.

In addition to the increase in circulating $\mathrm{FSH}$, the concentration of serum $\mathrm{LH}$ tended to increase on day 13 after birth in rats treated with $5 \mathrm{mg}$ busulfan $\mathrm{kg}^{-1}$. Whereas inhibin inhibits the synthesis and release of $\mathrm{FSH}$, it also decreases the release of $\mathrm{LH}$ from the pituitary gland. Pure $31 \mathrm{kDa}$ bovine inhibin has been shown to suppress $\mathrm{GnRH}$-induced upregulation of $\mathrm{GnRH}$ binding sites (Wang et al., 1989). A morphometric study indicated that the target cell of inhibin was a multihormonal gonadotroph that contains $\mathrm{LH}, \mathrm{FSH}$ and growth hormone (Childs et al., 1997). The decrease in the concentration of circulating inhibin might increase the number of $\mathrm{GnRH}$ receptors of pituitary cells containing FSH and $\mathrm{LH}$. These changes could increase LH secretion from the pituitary gland.

The present study focused on the effects of the size of the primordial follicle stockpile on initial and early recruitment of ovarian follicles by examining the concentrations of circulating hormones including 
ir-inhibin, a signalling peptide derived from healthy growing follicles in the ovary, and it was concluded that a reduction in size of the primordial follicle stockpile may reduce the number of primordial follicles that moved into the growing pool, the source of circulating ir-inhibin. Consequently, increased $\mathrm{FSH}$ may recruit more preantral and antral follicles to achieve puberty. The concentration of circulating inhibin during the neonatal and infantile periods was low; however, its change was the earliest gross change found in the offspring treated with busulfan. Various xenobiotics, such as Congo red, $\mathrm{VCH}$ and its active metabolite, cyclophosphamide, and several aromatic hydrocarbons, benzo[a]pyrene, 3-methyl-cholanthrene and 7,12-dimethyl-benz[a]antrathene, are known to target primordial, primary and preantral follicles (for review, see Hoyer and Sipes, 1996; Gray, 1997). In addition, aryl hydrocarbon receptor, the receptor for 2,3,7,8-tetrachlorodibenzo-p-dioxin and coplanar polychlorinated biphenyls, contributes to the slowing of the initial and early recruitment of follicles (Benedict et al., 2000). In evaluating the ability of various xenobiotics to affect the number of primordial follicles, the concentration of circulating inhibin during the neonatal and infantile periods may be a useful indicator in the rodent model.

The authors are grateful to the National Hormone and Pituitary Program, NIDDK, and A. F. Parlow for the rat LH and FSH radioimmunoassay kits. The authors are also grateful to G. D. Niswender (Animal Reproduction and Biotechnology Laboratory, Colorado State University, Fort Collins, CO) for the anti-oestradiol (GDN 244). This work was supported by Grants-in-Aid numbers 11460147 and 11839003 from the Ministry of Education of Japan.

\section{References}

Abel MH, Wootton AN, Wilkins V, Huhtaniemi I, Knight PG and Charlton HM (2000) The effect of a null mutation in the follicle-stimulating hormone receptor gene on mouse reproduction Endocrinology 141 1795-1803

Baarends WM, Uilenbroek JT, Kramer P, Hoogerbrugge JW, van Leeuwen EC, Themmen AP and Grootegoed JA (1995) Anti-Müllerian hormone and anti-Müllerian hormone type II receptor messenger ribonucleic acid expression in rat ovaries during postnatal development, the estrous cycle, and gonadotropin-induced follicle growth Endocrinology 136 4951-4962

Benedict JC, Lin T-M, Loeffler IK, Peterson RE and Flaws JA (2000) Physiological role of the aryl hydrocarbon receptor in mouse ovary development Toxicological Sciences 56 382-388

Burdick HO and Whitney R (1941) Ovulation induced in mice by single injection of follutein or untreated human pregnancy urine American Journal of Physiology 132 405-410

Burger HG (1999) The endocrinology of the menopause Journal of Steroid Biochemistry and Molecular Biology 69 31-35

Childs GV, Miller BT and Miller WL (1997) Differential effects of inhibin on gonadotropin stores and gonadotropin-releasing hormone binding to pituitary cells from cycling female rats Endocrinology 138 1577-1584

Dahl KD, Jia X-C and Hsueh AJW (1988) Bioactive follicle-stimulating hormone levels in serum and urine of male and female rats from birth to prepubertal period Biology of Reproduction 39 32-38
Döhler KD and Wuttke W (1974) Serum LH, FSH, prolactin and progesterone from birth to puberty in female and male rats Endocrinology 94 1003-1008

Döhler KD and Wuttke W (1975) Changes with age in levels of serum gonadotropins, prolactin, and gonadal steroids in prepubertal male and female rats Endocrinology 97 898-907

Dong J, Albertini DF, Nishimori K, Kumar TR, Lu N and Matzuk MM (1996) Growth differentiation factor-9 is required during early ovarian folliculogenesis Nature 383 531-535

Drummond AE, Dyson M, Thean E, Groome NP, Robertson DM and Findlay JK (2000) Temporal and hormonal regulation of inhibin protein and subunit mRNA expression by post-natal and immature rat ovaries Journal of Endocrinology 166 339-354

Durlinger ALL, Kramer P, Karels B, de Jong FH, Uilenbroek JTJ, Grootegoed JA and Themmen APN (1999) Control of primordial follicle recruitment by anti-Müllerian hormone in the mouse ovary Endocrinology $\mathbf{1 4 0}$ 5789-5796

Durlinger ALL, Gruijters MJG, Kramer P, Karels B, Ingraham HA, Nachtigal MW, Uilenbroek JTJ, Grootegoed JA and Themmen APN (2002) AntiMüllerian hormone inhibits initiation of primordial follicle growth in the mouse ovary Endocrinology 143 1076-1084

Fagbohun CF, Dada MO, Metcalf JP, Ashiru OA and Blake CA (1990) Blockade of the selective increase in serum follicle-stimulating hormone concentration in immature female rats and its effects on ovarian follicle development Biology of Reproduction 42 625-632

Gray LE (1997) Chemically induced alterations of reproductive development in female mammals. In Comprehensive Toxicology Vol. 10 pp 329-338 Eds K Boekelheide, P Chapin, P Hoyer and C Harris. Elsevier Science Ltd, Oxford

Hamada T, Watanabe G, Kokuho T, Taya K, Sasamoto S, Hasegawa Y, Miyamoto K and Igarashi M (1989) Radioimmunoassay of inhibin in various mammals Journal of Endocrinology 122 697-704

Hayashi M, McGee EA, Min G, Klein C, Rose UM, van Duin M and Hsueh AJW (1999) Recombinant growth differentiation factor-9 (GDF-9) enhances growth and differentiation of cultured early ovarian follicles Endocrinology 140 1236-1244

Herath CB, Yamashita M, Watanabe G, Jin W, Tangtrongsup S, Kojima A, Groome NP, Suzuki AK and Taya K (2001) Regulation of folliclestimulating hormone secretion by estradiol and dimeric inhibins in the infantile female rats Biology of Reproduction 65 1623-1633

Hirshfield AN (1994) Relationship between the supply of primordial follicles and the onset of follicular growth in rats Biology of Reproduction $\mathbf{5 0}$ $421-428$

Hooser SB, Douds DP, DeMerell DG, Hoyer PB and Sipes IG (1994) Long-term ovarian and gonadotropin changes in mice exposed to 4vinylcyclohexene Reproductive Toxicology 8 315-323

Hoyer PB and Sipes IG (1996) Assessment of follicle destruction in chemical-induced ovarian toxicity Annual Review of Pharmacology and Toxicology 36 307-331

Krarup T, Pedersen T and Faber M (1969) Regulation of oocyte growth in the mouse ovary Nature 224 187-188

Lee W-S, Otsuka F, Moore RK and Shimasaki S (2001) Effect of bone morphogenetic protein-7 on folliculogenesis and ovulation in the rat Biology of Reproduction 65 994-999

Lu KH, Hopper BR, Vargo TM and Yen SSC (1979) Chronological changes in sex steroid, gonadotropin and prolactin secretion in aging female rats displaying different reproductive states Biology of Reproduction $\mathbf{2 1}$ 193-203

McGee EA and Hsueh AJW (2000) Initial and cyclic recruitment of ovarian follicles Endocrine Reviews 21 200-214

Matzuk MM (2000) Revelations of ovarian follicle biology from gene knockout mice Molecular and Cellular Endocrinology 163 61-66

Merchant H (1975) Rat gonadal and ovarian organogenesis with and without germ cells. An ultrastructural study Developmental Biology 44 1-21

Meredith S, Dudenhoeffer G, Butcher RL, Lerner SP and Walls T (1992) Unilateral ovariectomy increases loss of primordial follicles and is associated with increased metestrous concentration of folliclestimulating hormone in old rats Biology of Reproduction 47162 168 
Parrott JA and Skinner MK (1999) Kit-ligand/stem cell factor induces primordial follicle development and initiates folliculogenesis Endocrinology 140 4262-4271

Pederson T and Peters H (1968) Proposal for a classification of oocytes and follicles in the mouse ovary Journal of Reproduction and Fertility 17 555-557

Richardson SJ, Senikas V and Nelson JF (1987) Follicular depletion during the menopausal transition: evidence for accelerated loss and ultimate exhaustion Journal of Clinical Endocrinology and Metabolism 65 1231-1237

Shimasaki S, Zachow RJ, Li D, Kim H, lemura S, Ueno N, Sampath K, Chang RJ and Erickson GF (1999) A functional bone morphogenetic protein system in the ovary Proceedings National Academy of Sciences USA $967282-7287$

Smith SS and Ojeda SR (1986) Neonatal release of gonadotropins is essential for development of ovarian follicle-stimulating hormone receptor Biology of Reproduction 34 219-227

Taya K, Mizokawa T, Matsui T and Sasamoto S (1983) Induction of superovulation in prepubertal female rats by anterior pituitary transplants Journal of Reproduction and Fertility 69 265-270

Taya K, Watanabe G and Sasamoto S (1985) Radioimmunoassay for progesterone, testosterone and estradiol- $17 \beta$ using ${ }^{125} \mathrm{I}$-iodohistamine radioligands Japanese Journal of Animal Reproduction 31 186-197

Ueno S, Takahashi M, Manganaro TF, Ragin RC and Donahoe PK (1989) Cellular localization of Mullerian inhibiting substance in the developing rat ovary Endocrinology 124 1000-1006
Vitt UA, McGee EA, Hayashi M and Hsueh AJW (2000) In vivo treatment with GDF-9 stimulates primordial and primary follicle progression and theca cell marker CYP17 in ovaries of immature rats Endocrinology 141 3814-3820

vom Saal FS, Finch CE and Nelson JF (1994) Natural history and mechanisms of reproductive aging in humans, laboratory rodents, and other selected vertebrates. In The Physiology of Reproduction Vol. 2 pp 1213-1314 Eds E Knobil and JD Neil. Raven Press, New York

Wang QF, Farnworth PG, Findlay JK and Burger HG (1989) Inhibitory effect of pure 31-kilodalton bovine inhibin on gonadotropin-releasing hormone $(\mathrm{GnRH})$-induced up-regulation of $\mathrm{GnRH}$ binding sites in cultured rat anterior pituitary cells Endocrinology 124 363368

Wise PM, Krajnak KM and Kashon ML (1996) Menopause: the aging of multiple pacemakers Science 273 67-70

Yoshida H, Takakura N, Kataoka H, Kunisada T, Okamura H and Nishikawa S (1997) Stepwise requirement of $c$-kit tyrosine kinase in mouse ovarian follicle development Developmental Biology 184122 137

Received 20 May 2002

First decision 17 July 2002.

Revised manuscript received 14 August 2002.

Accepted 17 September 2002. 